\title{
MALLARMÉ Y VASCO DE GAMA
}

La única alusión hispánica que contiene la obra poética de Mallarmé consiste en el nombre de Vasco, última palabra del soneto sin título cuyo verso inicial es $A u$ seul souci de voyager. Este nombre designa, con más evidencia para un lector francés que para el de habla española o portuguesa, al famoso explorador marítimo de fines del siglo xv. Pero, dada la dificultad de interpretación que suelen presentar los poemas de Mallarmé, y éste no menos que otros, transcurrió bastante tiempo sin que se apreciara exactamente el papel desempeñado por Vasco en el soneto. Medio siglo después de su publicación póstuma en la edición belga de las Poésies ${ }^{1}$, se descubrió que ya había figurado, meses antes de la muerte del poeta, en un Album conmemorativo del cuarto centenario del viaje de Vasco de Gama a la India². El soneto, pues,

1 Les poésies de S. Mallarmé, Bruselas, E. Deman, p. 198, 1898.

2 Album commémoratif publié sous le patronage de Sa Majesté la Reine Marie Amélie de Portugal, recueilli par Madame Juliette Adam, A Vasco de Gama, 1498. Hommage de la pensée française, 1898, Guillard, Ailland et Cia, éditeurs, 96 boulevard Montparnasse, Paris; 242 Rua Aurea, Lisboa, p. 41 (facsímil del manuscrito del poema, y texto impreso). En la "Bibliographie de l'édition de 1898" que Mallarmé escribió sobre la edición belga de sus poesias, y que también incluyen hoy las ediciones corrientes, informaba a "los escoliastas futuros" sobre algunos casos de publicación anterior, en revistas o libros, de poemas suyos que iban a figurar en esa nueva edición; pero nada dice respecto a nuestro soneto, y ni siquiera lo menciona: así es como pudo quedar ignorado el hecho de su previa publicación en el Album hasta 1947. fecha en que alli lo descubrió Auriant (véase su nota en el Mercure de France del mes de julio de aquel año, p. 585).-El Album se acabó de imprimir el 20 de abril de 1898; Mallarmé murió el 9 de septiembre del mismo año; el facsímil del Album reproduce seguramente un manuscrito por él comunicado a la editora, Madame Adam. Esta versión ofrece, como veremos, unas pocas variantes con relación al texto impreso en las Poésies de 1898 y reproducido en las ediciones posteriores (Poésies, Gallimard, 1913, y reediciones; Euvres, ed. H. Mondor y G.-J. Aubry, Bibliothèque de la Pléiade, y reediciones); este texto impreso debe proceder de otro manuscrito, que estaría en manos de Deman en 1898. De las dos versiones del poema que conocemos, la del Album y la de las Poésies, es muy probable que la segunda 
es en sí un homenaje a Vasco, y debemos leerlo como tal, con Vasco como héroe y no simple elemento de comparación. Si se pudo creer alguna vez que el soneto estaba dirigido a un amigo para su cumpleaños ${ }^{3}$, o dedicado en realidad a la memoria de Chateaubriand", el descubrimiento del Album, cuyo fin es celebrar oficialmente a Vasco de Gama, excluye este tipo de interpretación. Ello, claro está, no quiere decir que el soneto carezca de todo valor simbólico, ya que su héroe, objeto del poema en una lectura literal, puede perfectamente encarnar, en la intención del poeta, valores espirituales que exceden la materialidad de sus hazañas.

¿Cómo ha llegado Mallarmé a colaborar en un volumen consagrado a Vasco de Gama? No es que falten en su poesía otras navegaciones simbólicas ${ }^{5}$, pero en este Album, donde la Sra. Juliette Adam reunió textos de almirantes entusiastas y poetas heterogéneos que sólo saben elogiar la empresa marítima de Vasco y las fabulosas riquezas y maravillas de la India, no parece estar del todo en su lugar el exquisito y profundo $A u$ seul souci de voyager. La editora, que había gozado de gran notoriedad literaria y política en el París del Segundo Imperio y la Tercera República, se relacionó hacia 1895 con la reina María Amelia de Portugal, princesa de estirpe francesa: de allí la idea del oficial y lujoso Album patrocinado por la soberana ${ }^{6}$. Mallarmé ya conocía a Madame Adam desde hacía quince años; tenemos una carta de él dirigida a esta señora en que alude a su presencia repetida en las tertulias - hoy legendarias- de los martes en el salón parisino de los Mallarmé; pero el tono de dicha carta es el de una relación

es la definitiva y ofrece el resultado de correcciones hechas entre abril y septiembre, comunicadas por el poeta a su editor belga.

3 Es lo que sugiere Gardner Davies en el número especial sobre Mallarmé de la revista Les Lettres, juin 1948, p. 91.

4 Es la extraña tesis de A. Gill, $M L R$, 50 (1955), pp. 428 ss., aunque éste ya conocía la nota de Auriant y la presencia del soneto en un volumen consagrado a la gloria de Vasco.

ธ Véanse los poemas titulados Brise marine, Salut, $A$ la nue accablante $t u$ y el Coup de dés.

6 Juliette Adam viajó por Portugal en 1895, y publicó al año siguiente un libro titulado La patrie portugaise, en el que pueden leerse, p. 250, unas líneas elogiosas sobre la reina. María Amelia era biznieta del rey LouisPhilippe (1830-1848). Es probable que el Album fue subvencionado por Portugal. Contiene, además de artículos y poemas, facsímiles de piezas de música y gran cantidad de grabados originales sin relación alguna con Vasco; debió de ser de fabricación bastante costosa y el producto de su venta se destinó a una obra de caridad de la reina. Sobre la vida y la carrera de Juliette Adam (1836-1936), se puede leer: A. BLANc-Péridier, Une princesse de la Troisième République, Juliette Adam, Paris, 1936, y SAAD Morcos, Juliette Adam, El Cairo, 1961. 
mundana más que literaria ${ }^{\top}$. Si nos preguntamos quién, entre los colaboradores del Album, pudo introducir en él a Mallarmé, encontramos a Robert de Montesquiou, muy amigo del poeta, como se sabe; a Paul Adam, escritor simbolista y, sobre todo, a Camille Mauclair, discípulo ferviente del Maestro, al que dedicó artículos y libros ${ }^{8}$. Fue Mauclair quien muy probablemente debió de actuar de intermediario entre la editora del Album y Mallarmé para la publicación del soneto. A la vez que admirador de Mallarmé, era muy amigo de Juliette Adam, quien había acogido sus primeros ensayos en la Nouvelle Revue de la que era directora; el mismo Mauclair escribe: “Je n'ai rien dû qu'à deux êtres dans ma vie: Mallarmé m'a ouvert d'inoubliables horizons par la perfection de son esprit et la noblesse de sa vie; Madame Juliette Adam m'a accueilli avant tous, m'a fait comprendre comment on peut gagner sa vie avec sa plume sans subir ni offrir le mensonge" 9 . Otras confidencias de Mauclair indican que Mallarmé fue tema de conversación entre él y su protectora, que le dijo un día: "Vous m'expliquerez Mallarmé, dites? ... Je suis navrée de ne rien pouvoir lui demander, je ne comprends goutte à ce qu'il écrit"' ${ }^{10}$. Esa conversación tenía lugar hacia 1894, época de la entrada de Mauclair en la Nouvelle Revue; el soneto le fue seguramente pedido a Mallarmé para el Album poco antes de 1898. La proximidad de las fechas sugiere que Mauclair consiguió que se recibiera en el ecléctico Album lo que no podía entrar en la Revue: un poema hermético de su Maestro.

Además de la técnica particular de Mallarmé y del aspecto enigmático de su estilo, que tanto contrastan con el contenido ordinario, en verso o prosa, del Album, la originalidad, más notable aún, de su poema radica en hacer de la empresa del navegador portugués el símbolo de una aspiración jamás satisfecha a algo que siempre excede la realidad presente. Al substituir así la gloria de un viaje lleno de peligros y descubrimientos espléndidos por

7 Mallarmé, Correspondance, ed. Mondor-Austin, t. 2, Paris, 1965, p. 240.

s "L'esthétique de Stéphane Mallarmé", estudio recogido en L'art $d u$ silence (1901), y Les princes de l'esprit (hacia 1920); Le soleil des morts (1898), novela cuyo protagonista es, bajo otro nombre, el mismo Mallarmé; Mallarmé chez lui (1935), recuerdos piadosos sobre el Maestro.

9 Camille Mauclair, Servitude et grandeur littéraires, Paris, 1922, pp. 69 70. ("Nada he debido en mi vida sino a dos personas: Mallarmé me abrió inolvidables horizontes por la perfección de su espíritu y la nobleza de su vida; la señora Juliette Adam me hizo comprender cómo uno puede ganarse la vida con su pluma sin sufrir ni ofrecer la mentira").

10 Ibid., pp. 66-67 ("¿Me explicará Ud. a Mallarmé, por favor?... Me desespera no poder pedirle ninguna colaboración, pues no entiendo palabra de lo que escribe"). 
una pura e infinita ambición, transformó audazmente la figura de su héroe. Pero tal invención no fue del todo arbitraria, pues había preparado, dentro de la leyenda de Vasco, una evolución de la que $A u$ seul souci es el último eslabón, y que ahora trataremos de caracterizar brevemente.

El punto de partida de esta larga tradición poética lo constituyen Os Lusiadas, cuyo asunto fundamental es, como se sabe, el relato de la expedición portuguesa de 1498 capitaneada por Vasco. Este texto ilustre no sólo contribuyó poderosamente a asentar la celebridad del héroe lusitano, sino que transformó su empresa, medio siglo apenas después de su muerte, en motivo literario de universal resonancia. Tal como se presenta en la obra de Camões, el personaje de Vasco ofrece rasgos peculiares que, desde un principio, lo diferencian del clásico héroe épico. En efecto, si bien Camões se inspira constantemente en la epopeya antigua, en especial haciendo de su protagonista un héroe nacional a la manera de Eneas, el viaje de Vasco le brinda poca materia para los acostumbrados desarrollos bélicos propios del género: la navegación de 1498 no encontró mayores obstáculos guerreros ni tuvo que enfrentarse con peligros extraordinarios, siendo cosa sabida que Camões echó mano de episodios inventados para suplir la escasez de hazañas militares en la expedición ${ }^{11}$.

Cierto es que, al escoger como tema una aventura marítima, Camões se mostraba fiel a modelos clásicos de gran prestigio, siendo Vasco heredero moderno tanto de Ulises como de Eneas. Además, la visión camoniana, muy de su época, de la empresa portuguesa como cruzada cristiana en tierras extrañas es eco de la misión religiosa que Virgilio atribuye a Eneas, haciéndole transportar sus dioses desde Troya hasta el Lacio $^{12}$. Pero a pesar de todas estas características, que obedecen a las antiguas convenciones épicas, el personaje de Vasco no deja de apartarse en un aspecto esencial del tipo heroico de la antigüedad: simboliza el espíritu curioso, audaz y descubridor del hombre moderno, tal como surge en tiempos del Renacimiento. Tanto es así que, al exponerle al' rey de Melinde cómo Don Manuel y los miembros de su Consejo planearon la expedición de 1498, Vasco le explica que:

11 Esta carencia ha sido frecuentemente señalada por los críticos: véase, en 1776, el prólogo de La Harpe a su traducción de Os Lusiadas y G. LE Gentil, Camöens, Paris, 1954, p. 51; también A. J. Saraiva, “Os Lusíadas e o ideal renascentista da epopeia" en Para a história da cultura em Portugal, Lisboa, 1946, pp. 58-150.

12 Ver Lusíadas, I, 6, vs. 3-4; VII, 2 y 3; VII, 14, vs. 3-4; y sobre todo, VII, 25, vs. 7-8, en que queda así definido el intento de Vasco: "Vimos buscar do Indo a grão corrente, / Por onde a Lei divina se acrecente". (Citamos por la edición de Alvaro Júlio da Costa Pimpão, Lisboa, 1972. 
Determinan o náutico aparelho

Pera que, com sublime coração,

Vá a gente que mandar cortando os mares

A buscar novos climas, novos ares ${ }^{13}$.

Más tarde vuelve a expresar los mismos conceptos al contestar a las preguntas del rey de Calicut:

Sabe que há muitos anos que os antigos

Reis nossos firmemente propuseram

De vencer os trabahhos e perigos

Que sempre às grandes cousas se opuseram;

$\mathrm{E}$, descobrindo os mares inimigos

Do quieto descanso, pretenderam

De saber que fim tinham e onde estavam

As derradeiras praias que lavavam ${ }^{14}$.

Por ello Vasco es, en definitiva, una figura relativamente atípica con relación a sus antecesores homéricos o virgilianos.

Esta nueva tonalidad del ideal épico se combinó muy felizmente, en el caso que nos interesa, con un motivo antiguo que pertenece a la leyenda de Alejandro el Magno. El motivo, que se remonta a los primeros biógrafos de Alejandro, consiste en una anécdota que le atribuye el deseo de conquistas infinitas. Valerio Máximo, por ejemplo, escribe que al enterarse, por boca de su compañero Anaxarco, de la existencia, según Demócrito, de mundos innumerables, Alejandro exclamó: "Pobre de mí, que ni siquiera he logrado apoderarme de uno solo!"15. Este rasgo legendario ha gozado de una fortuna literaria muy diversa, transmitiéndola a través de los siglos a toda clase de autores y adquiriendo con el correr del tiempo significados varios ${ }^{16}$; en lo que nos inte-

13 Lusiadas, IV, 76, vs. 5-8.

14 Lusiadas, VIII, 70, vs. 1-4. El espíritu de estos versos vuelve a asomar en muchas otras partes de la obra camaniana que, como se sabe, se complace en señalar todos los descubrimientos científicos realizados por los portugueses; véase en particular, V, 14 ss., y V, 23.

15 Valerio Máximo, VIII, 14. La misma historia cuentan Plutarco en sus Obras morales (Tratado de la serenidad del alma, cap. IV, 466 C) y Eliano en sus Historias, IV, 29. Quinto Curcio pone en boca de Alejandro palabras que indican una intención análoga: "Ya no estoy lejos de los limites del universo; resolvi pasarlos y penetrar en otra naturaleza, en otro mundo" (Historias, IX, 6, 20); el contexto indica claramente en este caso, que Alejandro piensa concretamente en regiones desconocidas del orbe. Más sobrio, Juvenal resume la insatisfacción de Alejandro en una fórmula patética: "No cabe el desdichado dentro de los angostos límites del mundo", Sátira IX, vs. 168-169.

16 Dio lugar en particular a desarrollos medievales que recalcan el afán de conocimiento de Alejandro, representándolo como investigador y sabio ade- 
resa, fue recogido y relacionado precisamente con las hazañas portuguesas por João de Barros, cronista cuya obra fue una de las fuentes principales del poema camoniano ${ }^{17}$.

Barros utiliza en dos ocasiones el motivo en su Década $I$ publicada en 1552. Una vez en su Prólogo, aplicándolo al rey João III:

. . vóssas armas e padrōes de victórias tem tomádo pósse nam sómente de toda a térra maritima de África e Asia: mas ainda de outros mayóres mundos, do que Alexándre lamentáva, por nam ter noticia delies ${ }^{18}$;

la segunda vez en su Libro IV, refiriéndose al pueblo lusitano en su conjunto:

más de conquistador; entre muchos ejemplos europeos están las conocidas estrofas del Libro de Alexandre (2289-2291). Citamos por la edición de Dana A. Nelson, El libro de Alixandre, Madrid, 1979, p. 675.

\begin{abstract}
Dizen las escrituras - yo leí el tractadoque siete son los mundos que Dios ovo dado; de los siete el uno abés lo é domado, por esto yo non conto que nada he ganado.

Quanto avemos visto ante nós lo sabiemos; si ál non aprisiéssemos, en balde nós viviemos; por Dario nin por Poro, que vencido avemos, yo por esto non cuido que grant cosa fiziemos.

Enbió nos por esto Dios en estas partidas; por descobrir las cosas que yazen sofondidas; cosas sabran por nos que non serién sabidas, serán las nuestras nuevas en cántico metidas.
\end{abstract}

Consúltense a este respecto P. Meyer, Alexandre le Grand dans la littérature française du moyen âge, Paris, 1886, 2 ts.; María Rosa Lida DE Malkier, La idea de la fama en la Edad Media castellana, México-Buenos Aires, 1952, pp. 167.197, y "La leyenda de Alejandro en la literatura medieval" en La tradición clásica en España, Barcelona, 1975, pp. 165-197; G. CARY, The medieval Alexander, Cambridge, 1956, en particular pp. 101 y 284. Llama la atención el hecho que, ya en tiempos medievales, la leyenda de Alejandro haya revestido un significado intelectual semejante al que Camóes darí a las aventuras de su protagonista; por sugestivo que sea este parecido, cabe recordar, sin embargo, la distancia que separa el concepto de conocimiento en el siglo xin y en el xvi. Por otro lado atestigua la gran difusión del motivo en Europa su presencia en la obra de Molière, que lo utiliza jocosamente poniéndolo en boca de su Don Juan: "Il n'est rien qui puisse arrêter l'impétuosité de mes désirs: je me sens un coeur à aimer toute la terre; et comme Alexandre, je souhaiterais qu'il y eût d'autres mondes, pour y pouvoir étendre mes conquêtes amoureuses" (Dom Juan, acto I, esc. 2).

17 Sobre el material histórico utilizado por Camões -en particular las crónicas de Lopes de Castanheda y de João de Barros- véase J. M. RodrIGUes, Fontes dos Lusíadas, Coimbra, 1905, cap. 4, pp. 72 ss.

18 Asin de Joam de Barros... Primeira década, ed. A. Baião, Coimbra, 1932, p. 3 . 
...hua naçam, aque Deus deu tanto animo que, se tevera criado outros mundos, já lá tevera metido outros padrões de victórias ${ }^{19}$.

La fuerza expresiva del tema, tal como queda formulado en Barros, no se le escapó a Camões, quien aprovechó hermosamente el concepto en los versos ilustres que celebran la "pequena casa lusitana":

De Africa tem marítimos assentos;

E na Ásia mais que todas soberana;

$\mathrm{Na}$ quarta parte nova os campos ara

$E$, se mais mundo houvera, lá chegara ${ }^{20}$.

Acabamos de ver cómo, en la celebración de Vasco por la historia y por la poesía, asomaron muy temprano valores heroicos nuevos, más ajenos al ejercicio de la fuerza, más espirituales: será héroe en adelante, no sólo quien gana batallas o conquista territorios, sino quien extiende los límites de la condición humana y ensancha nuestro conocimiento del universo.

El conjunto temático que se vislumbra desde un principio en la leyenda de Vasco - Aventura y Exploración apasionada de lo desconocido- ha prosperado ampliamente en los siglos modernos, adquiriendo un valor simbólico de insaciable viaje metafísico más allá de lo alcanzable. Llegó a ser uno de los motivos centrales, y tal vez el mismo centro de la religión romántica. Ya ha señalado la crítica algunos textos del siglo XIX que relacionan expresamente el tema del Viaje espiritual con el recuerdo de Vasco de Gama. En su estudio de nuestro soneto, León Cellier dio a conocer páginas románticas notables a ese respecto ${ }^{21}$. Una de ellas es un poema de Víctor Hugo, del año 1830, que celebra la aventura de los descubridores antiguos como hazaña del espíritu humano, no satisfecho con lo visible; el poeta dice haber admirado desde niño a aquellos hombres

Qui, tourmentés d'une autre terre,

En ont deviné le mystère

Avant que rien en soit venu,

Dont la tête au ciel est tournéc,

Dont l'âme, boussole obstinée,

Toujours cherche un pôle inconnu!

19 Ibid., Livro IV, cap. 11, p. 160.

20 Lusiadas, VII, 14, vs. 5-8. La relación entre estos versos de Camōes con el prólogo de Barros ya lia sido señalada por G. LE GentiL, op. cit., p. 46.

21 León Cellier, Le pâle Vasco, en Reũue d'Histoire Littéraire de la France, 1958, p. 516; y versión rehecha del mismo estudio en su libro Mallarmé ct la morte qui parle, Paris, 1959, cap. 12 ("Lc: vaisseau fantôme"), pp. 215-216. 
Ces Gamas en qui rien n'efface

Leur indomptable ambition,

Savent qu'on n'a vu qu'une face

De l'immense création.

Ces Colombs, dans leur main profonde,

Pèsent la terre et pèsent l'onde

Comme à la balance du ciel,

Et, voyant d'en haut toute cause,

Sentent qu'il manque quelque chose

A l'équilibre universel!

Ce contrepoids qui se dérobe,

Ils le chercheront, ils iront... ${ }^{22}$

Se comprueba en estos versos la confusión deliberada entre el descubrimiento geográfico y la iluminación espiritual, función propia del poeta y pensador moderno.

No menos notables son estas líneas de George Sand, que también evocan el viaje de Vasco como símbolo de la trayectoria tormentosa y de incierto resultado de la generación romántica:

Nous avons tous doublé le Cap des Tempêtes autour duquel l'orage nous a tenus si longtemps errants et demi-brisés; nous sommes tous entrés dans l'Océan Pacifique, dans la résignation de l'âge mûr, quelques-uns voguant à pleines voiles, remplis d'espérance et de force, la plupart haletants et délabrés pour avoir trop souffert ${ }^{23}$.

Aquí domina el recuerdo de las pruebas y sufrimientos del Vasco legendario, convertidos en mito de la aventura espiritual román-

22 Victor Hugo, Les feuilles d'automne, poema IX, 'A Monsieur de Lamartine', estrofas 3 a 5 : “... Que codiciosos de otra tierra / Adivinaron su misterio / Antes que de ella nada nos llegara, / Guyo rostro mira hacia el cielo, / Cuya alma, brújula obstinada, / Siempre busca un polo ignoto. // Esos Gamas en quienes nada apaga / La indomable ambición, / Saben que sólo se ha visto una faz / De la inmensa creación. / Esos Colones, en su mano profunda, / Pesan la tierra y pesan el mar / Como en la balanza del cielo, / Y viendo desde lo alto todas las causas, / Sienten que le falta algo / Al equilibrio universal. // Ese contrapeso oculto / Ellos lo buscarán, ellos irán..." Hugo volvió a evocar a Vasco como símbolo de los descubrimientos y progresos espirituales de la humanidad en el famoso poema titulado Les Mages, que desarrolla en 1855 su profesión de fe de poeta misionario (Les contemplations, libro VI, poema 23 , sección 10 , estr. 8).

23 G. SAND, Lélia, prefacio de la edición de 1839, pp. ix-x: "Todos hemos doblado el Cabo de las Tormentas, en torno al cual la tempestad nos detuvo tanto tiempo errantes y maltrechos; todos hemos entrado en el Océano Pacífico, en la resignación de la edad madura, bogando algunos a toda vela y otros más jadeantes y lastimados por haber sufrido demasiado". 
tica. Pero la fórmula más perfecta del viaje sin fin hacia el ideal, nos la da Baudelaire, cuando escribe en Le Voyage (1859):

Mais les vrais voyageurs sont ceux-là seuls qui partent Pour partir; coeurs légers, semblables aux ballons, De leur fatalité jamais ils ne s'écartent, Et, sans savoir pourquoi, disent toujours: Allons!

Ceux-là dont les désirs ont la forme des nues, Et qui rêvent, ainsi qu'un conscrit le canon, De vastes voluptés, changeantes, inconnues, Et dont l'esprit humain n'a jamais su le nom! ${ }^{24}$

Estas estrofas ya no tienen el tono de optimismo y solemnidad humanitaria que caracterizaba a la generación anterior: en ellas asoma algo del desengaño post-romántico con respecto a los motivos ("sin saber por qué") y al fin ("deleites desconocidos") del Viaje. Pero es patente la continuidad esencial del tema en un verso como éste: "Notre âme est un trois-mâts cherchant son Icarie"25.

Ya existía, pues, una tradición que reúne en un todo simbólico la navegación de los descubridores del siglo xv -la de Vasco de Gama especialmente- con las ambiciones ideales del espíritu moderno y su máximo representante, el Poeta explorador y mago. Mallarmé no creó esta constelación de motivos, pero sí dio de ella en su soneto una versión original, más intensa que las demás:

(1) Au seul souci de voyager Outre une Inde splendide et trouble -Ce salut soit le messager Du temps, cap que ta poupe double

(5) Comme sur quelque vergue bas Plongeant avec la caravelle Ecumait toujours en ébats Un oiseau d'annonce nouvelle

(9) Qui criait monotonement Sans que la barre ne varie

24 Baudelaire, Les fleurs du mal, "Le Voyage", sección I: "Pero los verdaderos viajeros son aquellos que se van / Sólo por irse; corazones livianos cual globos de aire, / de su fatalidad jamás se apartan, / y, sin saber por qué, siempre dicen: ¡Vamos! / Aquellos cuyos deseos tienen forma de nubes, / y que sueñan, como sueña el soldado con el cañón, / Con vastos deleites, mudables, desconocidos, / Cuyo nombre nunca ha sabido el espíritu humano".

25 Ibid., sección II: "Nuestra alma es una nave en busca de su Icaria". Como se sabe, Icaria es la tierra ideal de la utopía comunista de Cabet (Voyage en Icarie, 1840). 
Un inutile gisement

Nuit, désespoir et pierrerie

(13) Par son chant reflété jusqu'au

Sourire du pâle $\operatorname{Vasco}^{26}$.

La obscuridad -tensión alusiva y laconismo en la condensación dentro de una frase única, de metáforas múltiples- que caracteriza este poema es la que Mallarmé llegó a considerar privilegio y obligación del lenguaje poético: con ella pensaba crear un alto grado de densidad, inaccesible a la elocución común, y proteger su poesía contra la lectura vulgar. Esta obscuridad creadora y defensiva oculta el sentido, pero en la poética de Mallarmé, lo implica y lo realza, siempre que el lector haga el indispensable esfuerzo de penetración y comunión con el habla del poeta. A dicho esfuerzo se le ha dado, en las últimas generaciones de críticos mallarmeanos, el pesado nombre de "exégesis", evocador de textos sagrados y comentarios infinitos. Lo que más bien hace falta es una rigurosa lectura, literal y sintáctica, que el verso de Mallarmé siempre sugiere y recompensa, y sin la cual no se puede gozar realmente de un poema suyo.

26 El soneto (octosilábico en el sentido francés, es decir no contando la última sílaba de las palabras llanas, $e$ "muda" o sea "femenina") consta, de acuerdo con el tipo shakespeariano, de tres cuartetos con sus rimas, rematados por un dístico final de rima propia; observa, por supuesto, la regla francesa de alternancia de rimas "femeninas" y "masculinas" (es decir llanas y agudas en la designación española). Las variantes del Album son: verso 3 , Ce salut va, le messager; verso 8 , Un oiseau $d^{\prime}$ ivresse nouvelle. El soneto, que sepamos, nunca fue traducido al español (véase una bibliografía de las traducciones españolas de poemas de Mallarmé hasta el año 1945, en Alfonso REyes, Mallarmé entre nosotros, México, 1955; Xavier Abril publicó más tarde una Antología de Mallarmé en castellano, Montevideo, 1961, que sólo parece recopilar traducciones anteriores: allí tampoco figura nuestro soneto). Nos permitimos, pues, para comodidad del lector y con toda humildad, la siguiente traducción:

1 Que al puro afán de viajar

Más allá de una India espléndida y turbia

Sea este saludo mensajero

Del tiempo, cabo que tu popa dobla

5 Como en alguna verga, hacia lo hondo

Moviéndose con la carabela

Aleteaba siempre cual espuma

Un pájaro de inaudita noticia.

9 Que monótonamente voceaba

Sin que variara el timón

Un inútil yacimiento

Noche, desesperanza y pedrería

13 A través de su canto reflejado hasta La sonrisa del pálido Vasco. 
El "puro afán de viajar", tema esencial de nuestro soneto y supremo valor que en él se celebra, abre gloriosamente el poema, pero gramaticalmente se subordina a lo que sigue, pues es un dativo: a él va dirigido "este saludo" o sea el soneto mismo, sujeto de la frase ${ }^{27}$. Mallarmé no nombra a Vasco, quien es en realidad el destinatario del saludo; quiere reservar su nombre para sorpresa y revelación final, y lo substituye por una abstracción, el "puro afán", que se supone caracterizarlo en forma eminente. Pero aunque no nombrado, Vasco es aludido en el segundo verso al mencionarse la India. Se entiende, pues, que el saludo va a un viajero que no puede conformarse con haber alcanzado la India y ansia ir más allá; y se nos aclaran sus razones en ese mismo verso: la India, que lo atrae por espléndida, lo repele por turbia. Ello su. giere que la magnificencia tiene algo impuro, por estar cargada de materia e inspirar tentaciones innobles.

El cuarto verso introduce a primera vista una idea muy distinta: el saludo que el poeta dirige a un viajero deseoso de ir más allá y desdeñoso de las riquezas índicas se presenta ahora como un "mensaje del tiempo". $Y$ es que señala un momento solemne en la carrera secular del héroe: el cuarto centenario de su hazaña. Luego surge, precisa, la imagen marítima - muy adecuada al temade Vasco que dobla el cabo del tiempo. De hecho, la primera versión, concreta y espacial, del motivo (cabo de tierra, verso 2), aunque puramente alusiva, importa más en un poema del Viaje que su versión abstracta y temporal (cabo del tiempo, verso 4); pues esta última, que sólo se refiere a la circunstancia del centenario, es después de todo un elemento accesorio con relación a la idea fundamental del poema.

Es de notar como esa sutil oscilación entre los dos sentidos de una misma imagen, Tierra desdeñada - Tiempo vencido- y, por fin, en todo el resto del poema, otra vez Tierra desdeñada, se realiza dentro del mayor rigor sintáctico y lógico. El paso final de este vaivén es el "comme" que inicia el segundo cuarteto: así como el Viajero, al cumplir cuatrocientos años de gloria, distancia hoy en su marcha sin fin el cabo inmóvil del tiempo presente ${ }^{28}$, que al verlo pasar le envía su saludo, asimismo Vasco doblaba, continuando su viaje, los cabos índicos cuyas riquezas le señalaba

${ }^{2 \tau} \mathrm{La}$ versión corriente dice: "Sea este saludo mensajero... al puro afán de viajar"; la variante del Album reza: "Este saludo va mensajero... al puro afán de viajar". La diferencia es minima.

28 El posesivo de segunda persona "ta" de este verso 5 no contradice la tercera persona implicada en el último verso, ni obliga a pensar, como creyeron algunos, que Mallarmé evoca en su soneto a dos figuras distintas; el cambio de persona es simple paso estilistico de la interpelación a la celebración pública. 
un pájaro nunca escuchado. En ambos casos, pasa sin detenerse, y esto basta para la lógica de la asociación; pero el vencer el tiempo significa sólo fama duradera; el desdeñar la India, indiferencia y menosprecio, y éste es el tema verdadero del soneto. La idea se desarrolla en la larga proposición, introducida por el "comme", que abarca los diez versos restantes (5-14). Al primer cuarteto, especie de exordio lírico, le sucede ahora una serie dramática de imágenes: escena objetiva en su tono, pero en realidad parábola del heroísmo espiritual. Primero aparece el pájaro anunciador de tierra, que se posa en una verga del mástil, moviéndose con la nave de arriba hacia abajo $^{29}$, pájaro blanco cuyo aleteo parece espuma marina $^{30}$. El carácter maravillosamente pictórico del cuarteto -visión en una docena de palabras de barco, mar y pájaro en movimiento- no deja olvidar, sin embargo, su intención simbólica: el pájaro no es solamente pájaro, sino que trae una noticia, un mensaje de importancia ${ }^{31}$. Las palabras "quelque" (v. 5), "toujours" (v. 7), "nouvelle" (v. 8), parecen sugerir que en el curso del viaje se ha repetido la intervención de una ave anunciadora en varios sitios sucesivos: no en una verga, sino siempre en alguna, volviendo a reproducirse la palpitante llegada con un llamado nuevo. Confirma esta interpretación el "monotonement" que viene luego (v. 9): monótona e insistente es la solicitación que se va repitiendo en el grito del pájaro, y su misma repetición es prueba de su poca eficacia; de hecho el timón 'no varía', no se desvía hacia la tierra,

29 "Bas plongeant", con el adjetivo hecho adverbio y antepuesto al verbo, es una expresión insólita; sin embargo, como ocurre casi siempre con las audacias lingüísticas de Mallarmé, tiene precedentes en idiotismos franceses de estructura análoga, por ejemplo "haut placé", "court vêtu".

30 "Ecumait ... en ébats" (literalmente: 'producía espuma ... en su aleteo') es otra expresión inusual; "ébats", propiamente 'retozos', es frecuente en Mallarmé con el sentido, aceptable en francés, de 'movimiento repetido', 'palpitación', aquí 'batir de alas'; además, el giro también tiene algún equivalente usual en francés: asi "éclater en pleurs", "se répandre en reproches". Por supuesto, el llanto como explosión, o los reproches como torrente, son menos sorprendentes que el batir de alas como espuma; pero en cambio éste tiene para Mallarmé, además de su valor poético, la ventaja de sugerir sin nombrarlo el color blanco del ave.

31 No hay que olvidar el parentesco de "annonce" con la mística "annonciation". EI Album trae aquí una variante de algún interés: "un oiseau $d$ " ivresse nouvelle"; "ivresse" es "embriaguez" o "arrebato". Se puede suponer que Mallarmé entendía "ivresse" con un valor algo negativo (fervor sensual, de sugestión tentadora), de acuerdo con el papel de mensajero del mundo material que el pájaro desempeña. Pero como "ivresse", en el vocabulario poético del siglo xIx, se usa más bien con connotación positiva, su substitución se puede explicar por el deseo de Mallarmé de eliminar cualquier sos. pecha de valoración del mensaje que Vasco ha de despreciar, 
y el yacimiento anunciado puede decirse 'inútil's2. Ese yacimiento precioso, ya evocado por medio de la alusión a la India "splendide et trouble", aquí se califica, de modo también ambivalente "nuit, désespoir et pierrerie": noche, por estar encerrado en las tinieblas de la tierra, desesperanza de su inutilidad, y pedrería como si el diamante mismo fuera producto de la nada ${ }^{33}$. Pero esas mismas calificaciones pueden aplicarse a la tentación que de él emana: noche a la vez desesperada y deslumbradora de la codicia.

Pájaro y pedrería no consiguen de Vasco más que una sonrisa. ¿Qué proceso conduce, en el soneto, a tal sonrisa? El grito del pájaro la ha de producir mediante una inducción lógica; la serie causal es: pedrería-grito animal-pensamiento humano-sonrisa en un rostro. Así, por supuesto, sucede en la realidad, y no puede ser de otra manera. Pero el poeta, alterando ese proceso demasiado explícito, imagina que la luminosidad mineral escondida en la tierra se transmite en forma de sonrisa a la cara del hombre. Finge que el brillo enterrado de la pedrería tiene su reflejo revelador en el canto del pájaro; así lo dice claramente el texto: "un inutile gisement... reflété par son chant" 34 . La sensación visual se transforma en otra auditiva; pero el poeta, callando los pensamientos de su héroe, cuya clave no nos da, sólo nos deja ver su resultado visible: la sonrisa de Vasco, pálida reconversión del canto-reflejo que ha llegado hasta él. La extraordinaria serie sensorial, Brillo oculto-Grito aéreo-Sonrisa pálida, condensa en tres imágenes lacónicas, misteriosamente transformadas una en otra, todo el drama de la tentación y el rechazo. La sonrisa final de Vasco, si dice poco, significa mucho: es luz atenuada, heroísmo melancólico de quien, en busca de un ideal lejano e incierto, se mantiene a distancia de la vida.

Es evidente que el héroe de Mallarmé, si bien es efectivamente Vasco de Gama, homenajeado en el cuarto centenario de su viaje a la India -y no, como pudo creerse, algún otro destinatario representado por Vasco- simboliza, sin embargo, algo más que Vasco

32 La palabra "gisement" ha sido objeto de una nutridisima discusión, en la que participó y se dividió toda la crítica mallarmeana. Resumamos brevemente el asunto. "Gisement", en su acepción más común, es en francés "yacimiento" (en este caso, de minerales preciosos); pero como término de marina significa "situación de una costa". Cualquiera de los dos significados conviene aquí, pudiendo el pájaro anunciar tanto minas de oro o diamante como la posición de la costa cercana; si preferimos atenernos al sentido mineralógico, es porque se dice que el "gisement" está reflejado en el canto del pájaro, lo cual nos parece más propio de un brillo mineral que de las cifras abstractas de una posición geográfica.

as Véanse, sobre este conjunto de motivos, las observaciones de J. P. Richard, L'univers imaginaire de Mallarmé, Paris, 1961, pp. 187-188.

34 "Par son chant reflété" es, claro está, una inversión poética; "reflété" califica "gisement". 
mismo. El lector vislumbra, detrás del Descubridor desdeñoso de su descubrimiento, la figura del poeta, nunca contento con lo real, dedicado por ley de su arte a una búsqueda sin fin, y condenado a desear, más allá de lo que inventa su verso, otros inventos y otras palabras más esenciales, anhelando siempre lo que no puede alcanzarse ni conocerse. Así lo sospecharon, en general, los comentaristas de nuestro soneto, aun cuando propusieron otras explicaciones menos plausibles. No conviene entrar aquí en el detalle de esas divergencias; nos apartarían demasiado de Vasco, de quien no queremos alejarnos ${ }^{35}$.

En el proceso que acabamos de estudiar, el "pálido Vasco" llegó a representar para Mallarmé al Poeta en su afán de lo ideal. Pero hay que confesar que, entre su punto de partida histórico y su punto de llegada en el soneto, el personaje ha sufrido una extraña metamorfosis. El Vasco de la Historia ambicionaba con llegar hasta la India, y de ninguna manera pensaba ir más allá. Los relatos antiguos de su viaje no dejan lugar a dudas al respecto. El diario escrito por un participante de la expedición -único testimonio directo y contemporáneo del que disponemos- relata que, cuando Vasco llegó a Calicut, encontró allí a un moro originario de Túnez que hablaba español; éste, muy asombrado de ver gente portuguesa en la India, le preguntó qué venían a buscar tan lejos de su patria: "E elle lhe rrespondeo: Vimos buscar xristãos e espeçiaría" 36 . Las especias eran, pues, el fin material de la empresa, siendo su fin espiritual establecer relaciones con legendarias comunidades cristianas y lograr así, la unificación de la fe verdadera. Medio siglo después, João de Barros nos informa de modo igualmente significativo sobre el concepto que de la meta de su expedición tenían los compañeros de Vasco; al verse por fin en la India, escribe Barros,

...a qual como era o termo de sua navegaçam, e na instruçã que leváva nenhua outra cousa lhe éra mais encomendáda, e pera o rey della nomeádamente leváva cártas e embaixáda, como ao mais poderóso principe daquellas pártes e senhor de todalas especearias, segundo a noticia que naquelle tepo neste reyno de Portugal tinhamos delle: pareceo aos nossos vendose diante della que tinhã acabádo o fim de seus trabálhos ${ }^{37}$.

35 Entre los comentarios a este soneto, consúltense Madame E. Noulet, L'cuvve poétique de Stéphane Mallarmé, Paris, 1940, y Vingt poèmes de Stéphane Mallarmé, Paris-Geneve, 1967; Сн. Chassé, Les clefs de Mallarmé, Paris, 1954; A. Gill, art. cit.; L. Cellier, art. y op. cit.; y A. R. Chisholm, "Mallarmé's Vasco sonnet", FS, 20 (1966). p. 36.

36 Diário da viagem de Vasco da Gama, ed. D. Peres, Coimbra, 1945.

37 Década I, ed. cit., Livro IV, cap. 6, p. 143. 
No parece haber habido por parte de Vasco de Gama desdén hacia la India -sino al contrario intensa atracción- ni proyecto alguno de pasarla por alto y seguir navegando más allá38. En cambio, las palabras "outre une Inde" son el núcleo de la alabanza que Mallarmé le dedica, y esas palabras, al suponer la India menospreciada, sobreentienden un fin ideal informulado y quizá informulable, del todo ajeno a los propósitos y al modo de pensar del Vasco real y sus contemporáneos.

Tenemos, pues, aquí un ejemplo de transmisión, en literatura culta, de un tema que al viajar por el tiempo cambia de sentido hasta volverse del todo distinto de lo que era en su origen: Vasco deja de ser Vasco de Gama para hacerse alegoría de otra cosa. Se podrían señalar más casos de reinterpretación simbólica, en nuestros tiempos, de personajes que, en su carrera anterior, actuaban dentro del mundo real. Tales cambios se deben seguramente a los de la sociedad misma a lo largo de los siglos; si se ha podido pasar del Vasco de Gama navegador a un Vasco pensador o poeta es porque, dentro del sistema de valores socialmente admitidos, se ha ido glorificando siempre más, entre el siglo xvi y el xx, la creación espiritual a expensas de la pura grandeza material, y porque se ha valorizado al filósofo, artista y poeta con detrimento del hombre de acción.

Pero si dejamos a un lado el significado sociológico de la evolución de nuestro tema, para considerar tan sólo su aspecto técnico y formal, notamos que, en este caso como en tantos otros, la forma varía menos que el pensamiento que en ella vive. Una vez admitidos, los tipos y los esquemas literarios se vuelven, por así decirlo, institucionales, y quedan más fijos y arraigados en la costumbre que las ideas; su modificación requiere más trabajo por parte del sujeto innovador. Es más difícil inventar una palabra nueva que darle un sentido nuevo a una palabra corriente; no hay diccionario del idioma que sea que no lo atestigüe. Igual pasa en literatura: cuesta menos elaborar un Vasco de Gama nuevo que inventar otro héroe. Esto nos conduce a una observación más, y es que el juego de variación dentro de un mismo tema tiene sus límites, y supone algún elemento fijo que haga posible la permanencia, en el curso de

38 En Os Lusiadas, VII, 60 ss., Vasco comunica al rey de Calicut, el Samorim, de parte de su soberano Dom Manuel, un mensaje de amistad y la oferta de un pacto comercial. Y más tarde, Lusiadas, VIII, 73, insiste en que la India es el término de su misión y que de allf piensa regresar llevándole a su rey la respuesta que éste espera. Lo que se lee al principio del poema camoniano: "aínda além da Taprobana" (Lusiadas, I , I, v. 5) se refiere a exploraciones ajenas a las de Vasco, emprendidas posteriormente por los portugueses, siendo Taprobana el nombre antiguo de una isla diversamente lo. calizada a la que Camões identifica con Ceilán. 
dicha variación, de la forma primitiva. Aquí, por ejemplo, lo que se mantiene es el concepto de un desafío humano: en el caso del Vasco histórico, desafío al espacio mantenido y ampliado en Camóes; en el romanticismo, y sobre todo en Mallarmé, desafío a la limitada condición espiritual del hombre. De alterarse o desaparecer este concepto, o de faltar quien le desee inventar variantes nuevas, el linaje literario que hemos tratado de recorrer se interrumpiría, y quedaría inmovilizado en su última etapa: $A$ u seul souci.

Sylvia Roubaud

Paul BéNichou

Paris-Sorbonne.

Harvard University.

Con estas páginas saludamos la memoria de Raimundo Lida que también acaba de alejarse de nosotros "doblando un cabo del tiempo". Y al elegir el tema se nos ocurrió -ipor qué no decirlo? - una semejanza más intima entre la simbólica figura del soneto y nuestro Raimundo, él también investigador exigente, nunca satisfecho y serenamente inaccesible a la tentación de la facilidad. 